\title{
Vladimír Kořínek
}

Bemerkung zu der Arbeit: „Die Anwendung der Polarität auf die direkten Produktzerlegungen einer Gruppe" von František Šik

Czechoslovak Mathematical Journal, Vol. 6 (1956), No. 1, 139

Persistent URL: http://dml.cz/dmlcz/100184

\section{Terms of use:}

(C) Institute of Mathematics AS CR, 1956

Institute of Mathematics of the Czech Academy of Sciences provides access to digitized documents strictly for personal use. Each copy of any part of this document must contain these Terms of use.

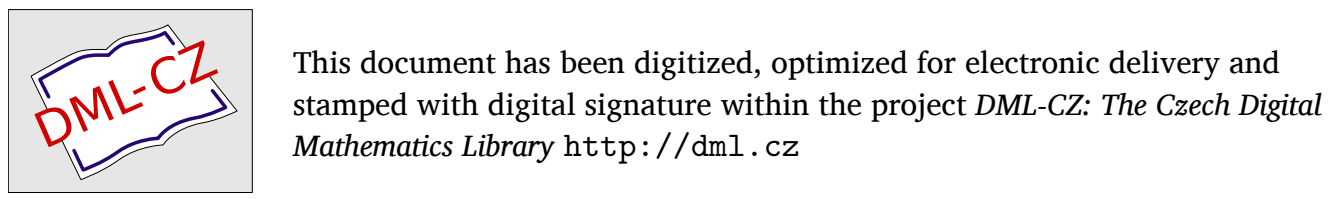




\section{BEMERKUNG ZU DER ARBEIT: \\ „,DIE ANWENDUNG DER POLARITÄT AUF DIE DIREKTEN \\ PRODUKTZERLEGUNGEN EINER GRUPPE““ \\ VON FRANTIŠEK ŠIK}

VLADIMIR KOŘ́nEK, Praha

(Eingelangt am 21. V. 1955.)

In seiner Arbeit „,Die Anwendung der Polarität auf die direkten Produktzerlegungen einer Gruppe", diese Zeitschrift, 5, 1955, 61-75, machte Herr Frant. Sik auf S. 74 die Bemerkung, dass ich ihn aufmerksam gemacht hatte, der Satz aus $\S 5$ seiner Arbeit liesse sich allgemeiner fassen. Herr Sik gab auch in der Fussnote ${ }^{10}$ ) diese allgemeinere Fassung und fügte noch eine Bemerkung betreffend den Beweis dieser Verallgemeinerung hinzu. Das kann folgendermassen zustande: Auf Anlass des Redaktionsrates schrieb ich ausführliche Bemerkungen zu der Arbeit. Darin äusserte ich die Meinung, der Satz habe nichts mit der in der Arbeit entwickelten Komponententheorie zu tun. Zu Unterstützung dieser meinen Meinung wies ich darauf hin, dass der Satz sogar in einer allgemeineren Fassung gruppentheoretisch unmittelbar einleuchtet und trivial ist. Ich lege selbstverständlich an diese Verallgemeinerung keinen Wert, obzwar aus der Fussnote ${ }^{10}$ ) das Gegenteil scheinen könnte. Die Fussnote auf S. 74 entstand durch Missverständnis meiner oben erwähnten Bemerkungen. 